\title{
Surface Amorphous and Crystalline Microstructure by Alloying Zirconium Using Nd:YAG Pulsed Laser
}

\begin{abstract}
X.L. WU and Y.S. HONG
A novel composite coating was synthesized by laser alloying of zirconium nanoparticles on an austenite stainless steel surface using a pulsed Nd:YAG laser. The coating contained duplex microstructures comprising an amorphous phase and an austenitic matrix. A discontinuous zirconium-containing region formed at a depth of $16 \mu \mathrm{m}$ below the surface. The amorphous phase was present in the zirconium-rich region, with the composition of zirconium ranging from 7.8 to 14.5 at. pct. The formation of the amorphous phase was attributed to the zirconium addition. The hardness, corrosion, and wear-corrosion resistance of the irradiated coating were evidently enhanced compared to those of the stainless steel.
\end{abstract}

\section{INTRODUCTION}

RICKEROY and Matthews ${ }^{[1]}$ proposed that surface engineering aims at designing a composite system, i.e., coating plus substrate, with a performance that cannot be achieved by either the coating or the substrate alone. Laser surface alloying is a most promising technique, because it can obtain the desired composition and microstructure, thus providing remarkable improvements in surface hardness, fatigue, wear, and corrosion resistance of materials without impairing their bulk properties. ${ }^{[2]}$ Microstructure changed tremendously after laser alloying, i.e., refinement and homogenization of microstructure, extension of solid solubility and formation of nonequilibrium phases (noncrystalline phases and metastable crystalline phases).

The focus of this study was laser surface alloying of an austenite stainless steel. The austenitic stainless steel is widely used owing to its high corrosion resistance, but due to its low hardness, its tribological properties were very poor. Moreover, because of its austenitic structure, it cannot be hardened by heat treatment and, therefore, there was no easy method for improving its wear resistance.

Various investigations have been performed on synthesizing the particulate-reinforced metal matrix composite surface coating on stainless steels using laser surface alloying. As a result, hard and wear-resistant surfaces were produced. AISI 304 stainless steel was hardened by laser melt injection of 140-70 mesh TiC particles. ${ }^{[3]}$ The microhardness of the austenitic matrix increased from 150 to about 200 to 250 $\mathrm{Hv}$. Laser alloying of a 12 pct $\mathrm{Cr}$ stainless steel with $\mathrm{Cr}_{2} \mathrm{O}_{3}$ powder was also studied. ${ }^{[4]}$ The surface-alloyed region exhibited a microhardness of about $1100 \mathrm{Hv}$ due to the dispersion and precipitation of chromium carbides in addition to the martensitic structure. Laroudie et al. ${ }^{[5]}$ investigated the surface hardening of the AISI 316 stainless steel by laser alloying with various precursors leading to the precipitation of hard carbides during the solidification. Rieker et al. ${ }^{[6]}$ improved the abrasive wear resistance of a stainless steel by laser alloying with molybdenum and boron. Laser

X.L. WU, Associate Professor, and Y.S. HONG, Professor, are with the State Key Laboratory of Nonlinear Mechanics, Institute of Mechanics, Chinese Academy of Sciences, Beijing 100080, People's Republic of China.

Manuscript submitted February 29, 2000. alloying of 304 stainless steel, with molybdenum alone, led to an increase in hardness from 200 to $400 \mathrm{Hv}$ for a surface alloy containing $10 \mathrm{wt}$ pct of molybdenum. ${ }^{[7]}$ Other authors studied the laser alloying of stainless steels with boron ${ }^{[8]}$ and carbon. ${ }^{[9]}$ In both cases, an increase in hardness vs the quantities of boron and carbon incorporated was evidence.

The component surface treated for wear resistance is finding more use in harsh environments. For example, it was of much interest in design material that exhibited both superior wear resistance and corrosion resistance. ${ }^{[10]}$ Unfortunately, the same microstructural changes that enhanced wear resistance adversely affected corrosion resistance. ${ }^{[11]}$ For example, the particulate-reinforced wear-resistant coating necessarily made of a composite material different from the base metal opens up the possibility of galvanic corrosion either at the interface between the particulate and the binder alloy or at the bond area between the coating and the substrate.

The laser surface amorphization technique is emphasized and being rapidly developed. ${ }^{[12,13]}$ Various types of laser, e.g., $\mathrm{CO}_{2}$, ruby, and YAG, with a large range of interaction times (picosecond to millisecond), have been used. The pulsed YAG laser has very short duration laser pulses and could induce an ultra-high-temperature gradient and cooling rate in rapidly solidified surface layers. The amorphous phase produced has high mechanical strength, ductility, and superior corrosion resistance. Therefore, a coating containing the amorphous phase may be an effective way of optimizing both the wear and corrosion resistance of materials. To our knowledge, however, the synthesis of the layer containing the amorphous phase on the stainless steel substrate by laser surface alloying has not yet been explored.

Proposed is an exploratory study on surface amorphization of an austenitic stainless steel by laser surface alloying using a pulsed Nd:YAG laser, The process consisted of melting the surface of the base alloy with precoated zirconium nanoparticles, mixing these components, and allowing them to solidify rapidly. The process led to formation of a surface layer with chemical composition and properties different from those of the substrate material. Coating consisted of the dual-phase microstructure, i.e., the fine cells and dendrites of austenite and the iron-based amorphous phase. Therefore, the coating can be expected to have good wear and corrosion resistance, due to the high strength and superior corrosion 
resistance of the amorphous phase. Presented here is a comprehensive analysis of microstructure of the coating.

\section{EXPERIMENTAL PROCEDURE}

An austenitic stainless steel was chosen as the substrate. The chemical composition (wt pct) was $0.06 \mathrm{C}, 18.95 \mathrm{Cr}$, $8.85 \mathrm{Ni}, 0.82 \mathrm{Ti}, 0.028 \mathrm{P}, 0.023 \mathrm{~S}$, and balance Fe. The heat treatment included austenitization at $1373 \mathrm{~K}$ for $2 \mathrm{~h}$ followed by quenching in water. The dimension of samples was 60 $\times 40 \times 25 \mathrm{~mm}$.

The pulse Nd:YAG laser with a wavelength of $1.06 \mu \mathrm{m}$ was used. Processing parameters for laser texturing were selected as follows: single pulse, beam spot size on the sample of $200 \mu \mathrm{m}$, pulse duration of $180 \mathrm{~ns}$, an average output power of $250 \mathrm{~W}$, and a frequency of $12 \mathrm{kHz}$.

A layer is precoated on the sample surface with the aim of reducing gasification, increasing laser absorption of the material leading to large pool depth, and strengthening the pool by forming new kinds of phases through laser alloying under the present laser texturing condition. The alloying element was selected to be zirconium particles with a size of about $6 \mathrm{~nm}$ and purity of 99.9 pct. The $\mathrm{Zr}$ particles were blended with an organic solution. The solution was sprayed evenly on the entire sample surface using a sprayer gun equipped with a stirring apparatus. The precoated layer had an even thickness of about $220 \mathrm{~nm}$. The sample was put on an X-Y table with circulating water for cooling during laser irradiation. After every shot of laser pulse, the stable moved successively by a distance of $220 \mu \mathrm{m}$ at a time interval of 0.1 seconds. So, the molten pool arranged regularly on the sample surface, with the center distance between two pools being equal to the diameter of the pool. A stream of argon blew over the irradiated surface to prevent oxidation.

Microstructures were analyzed using optical metallography, scanning electron microscopy (SEM), transmission electron microscopy (TEM), and high-resolution transmission electron microscopy (HRTEM). Chemical composition was determined using energy-dispersive X-ray analysis (EDXA) in conjunction with SEM with an apparatus error of 0.1 at. pct. Several times of line scanning were made along the depth direction of the pool. The electron beam of TEM/EDX produced an electron spot of $5 \mathrm{~nm}$ in diameter. Thin TEM wafers were prepared as follows. The first step was to cut a bar ( $3 \mathrm{~mm}$ in diameter and $20 \mathrm{~mm}$ in length) from the irradiated sample. The longer axis was taken normal to the laser-exposed surface. Thin wafers of 5- $\mu \mathrm{m}$ thickness were cut using a diamond knife normal to the long axis of the bar. Several successive cuts were collected, which therefore allowed the inspection of a well-identified depth of the pool. Thin wafers were subsequently ion milled and perforated under a voltage of $5.5 \mathrm{kV}$.

Hardness of the coating was calculated from the load vs displacement data obtained by means of a CMES (Swiss Center for Electronics and Microtechnology, Neuchatel, Switzerland) automatic nanoindenter. This load-controlled apparatus drives a diamond Berkovich (Swiss Center for Electronics and Microtechnology, Neuchatel, Switzerland) indentor at a constant loading rate. While indentation experiments proceeded, the loading-unloading response of the sample was recorded. The system had load and displacement resolution of $0.3 \mu \mathrm{N}$ and $0.17 \mathrm{~nm}$, respectively. The system was thermally buffered from its surroundings and the room in which it was housed was temperature-controlled to \pm 1 ${ }^{\circ} \mathrm{C}$. Several times of hardness tests were made along the direction depth of the pool. The apparatus error of hardness was $0.02 \mathrm{GPa}$.

Wear-corrosion experiments were carried out in $2.5 \mathrm{M}$ sodium chloride solution using a saturated calomel electrode reference electrode at the temperature of $298 \mathrm{~K}$. A polymethyl methacrylate cell was present, which contained the test solution and acted as an electrochemical cell. In the cell, there was a transmission shaft with a counterface connected to the electrical motor. There was another moving rod with the sample and the system-imposing load. The sample position was adjustable to obtain the best test condition. Column samples for the wear-corrosion test were cut from the laserirradiated sample, with a shape of diameter $15 \mathrm{~mm}$ and thickness $8 \mathrm{~mm}$. The sample was embedded in a polyester resin leaving only the alloyed area free, and the other parts were carefully covered to avoid crevice corrosion problems. The electrical contact was made with electrical wire, also embedded in resin, connected by brazing on the reverse side of the sample. Hence, wear testing was carried out under pure sliding (block on disc). The surface of the mounted sample was abraded by the rotating shaft with $\mathrm{SiC}$ paper of average size 500 mesh attached to the motor with a rotation speed of $12 \mathrm{rpm}$ and at a load of $2 \mathrm{~N}$. The wear-corrosion speed was obtained by the weight-loss method. Weight measurements were obtained with an analytical balance of 0.01 $\mathrm{mg}$ resolution. The polarization curve during wear was measured with conducting the scan from -1 to $+2 \mathrm{~V}$ at a speed of $1 \mathrm{mV} / \mathrm{s}$. The obtained results were average data of three samples.

\section{EXPERIMENTAL RESULTS}

\section{A. Morphology of Rapid Solidification}

Figures 1(a) and (b) are optical morphologies showing the cross-sectional view and top view of the molten pool, respectively. The maximum depth of the alloyed layer is about $60 \mu \mathrm{m}$. The microstructure consists of fine cells and dendrites because of rapid solidification.

Figure 2 shows the result of the composition analysis of zirconium determined by SEM/EDXA. It comprises results of three line-scanning analyses along the pool depth. Two distinct zones are seen in the pool: the layer just below the surface (i.e., the first $16 \mu \mathrm{m}$ ) and the deeper layer. The zirconium-contained region is present up to about $16 \mu \mathrm{m}$ below the surface. The zirconium distribution within this layer is discontinuous and uneven. In the deeper layer of the pool, zirconium is absent. This is because pulsed laser has a super short effect period. The convection exists only in the top part of the pool and full diffusion of alloyed elements cannot be realized.

\section{B. Microstructure}

Figure 3 is the bright-field TEM image showing microstructures in the zirconium-contained zone of the pool. Cells of austenite appear with a high density of twins and dislocations, as shown in Figures 3(a) and (b) respectively. These ultrafine cells, with several hundreds of nanometers, come from the transition from dendrite to cell when the solid/ 

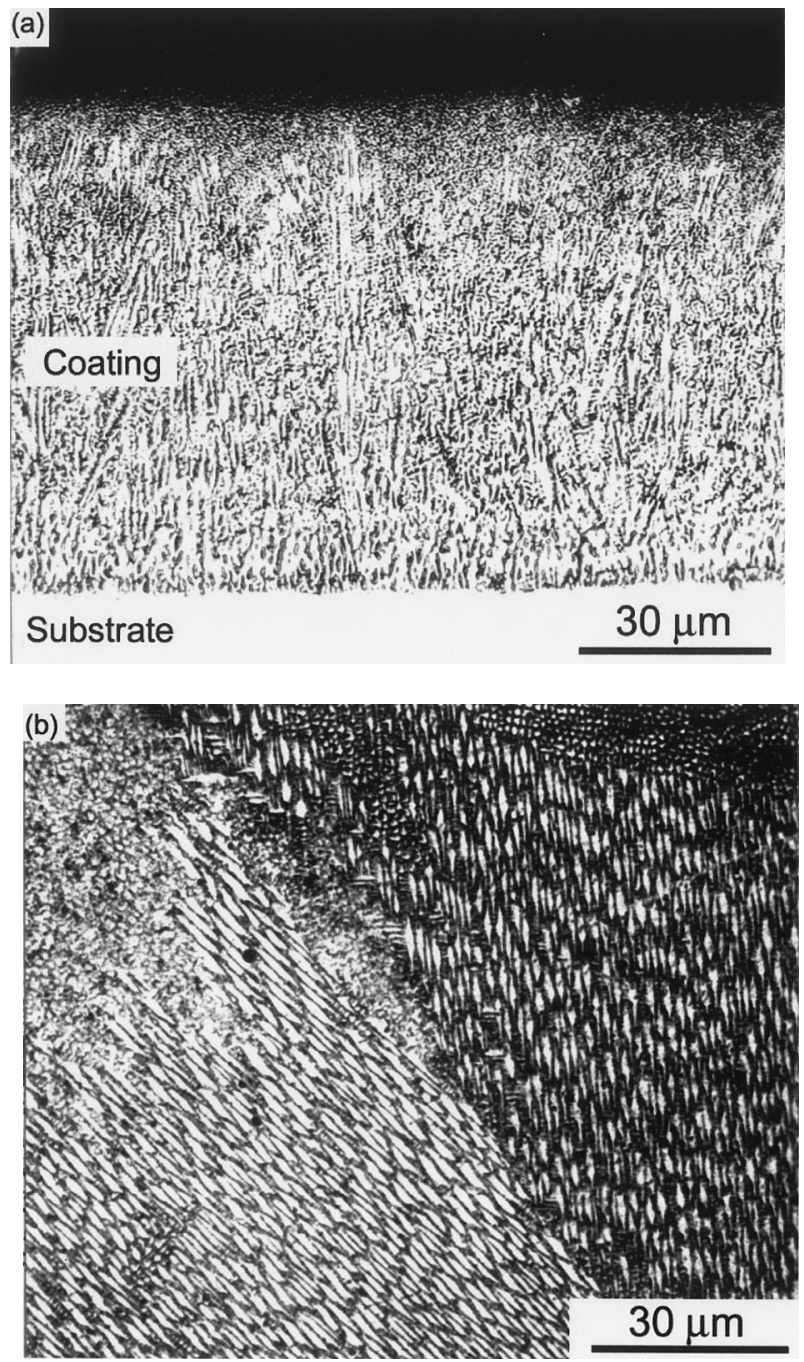

Fig. 1-Optical morphologies of the (a) cross-sectional view and $(b)$ top view.

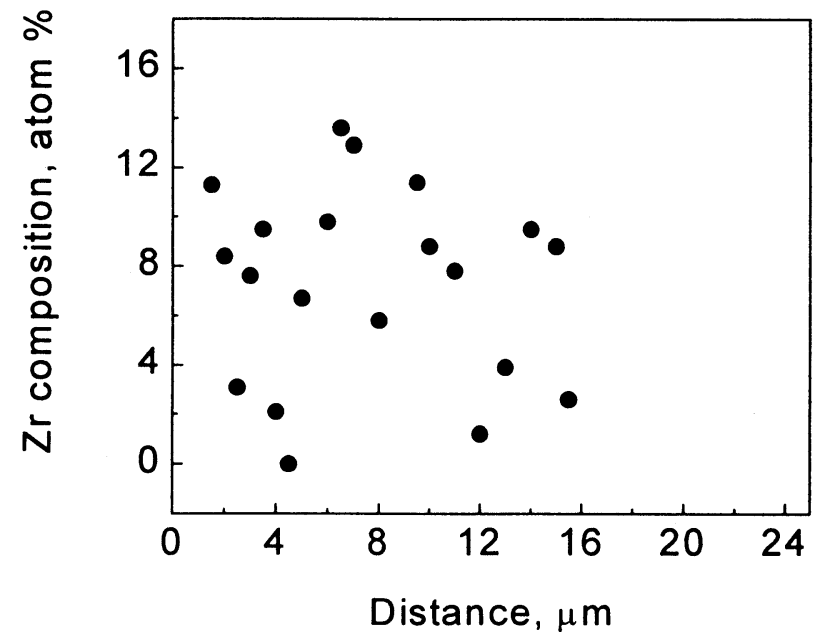

Fig. 2-Distribution of zirconium as a function of depth of the pool by SEM/EDXA.

liquid interface advances at the high rate in the upper region of the pool.
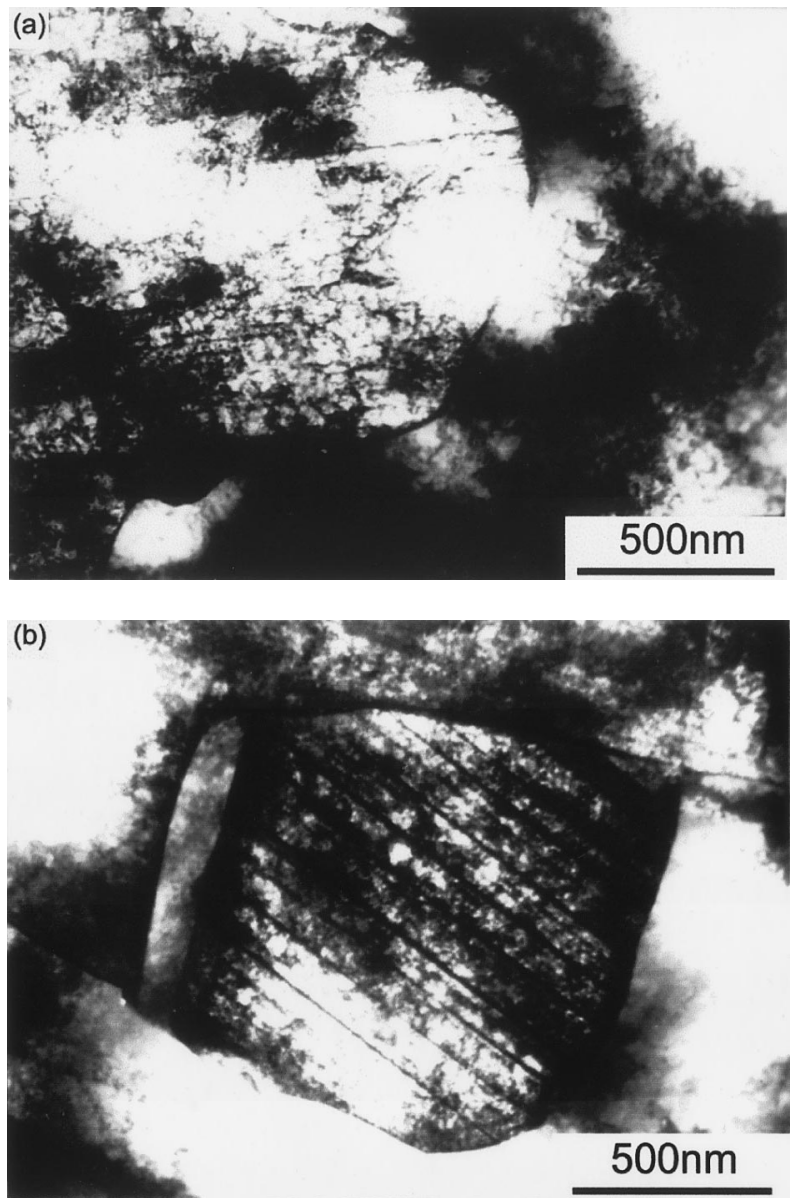

Fig. 3-TEM images showing austenitic cells with (a) dislocations and (b) twins.

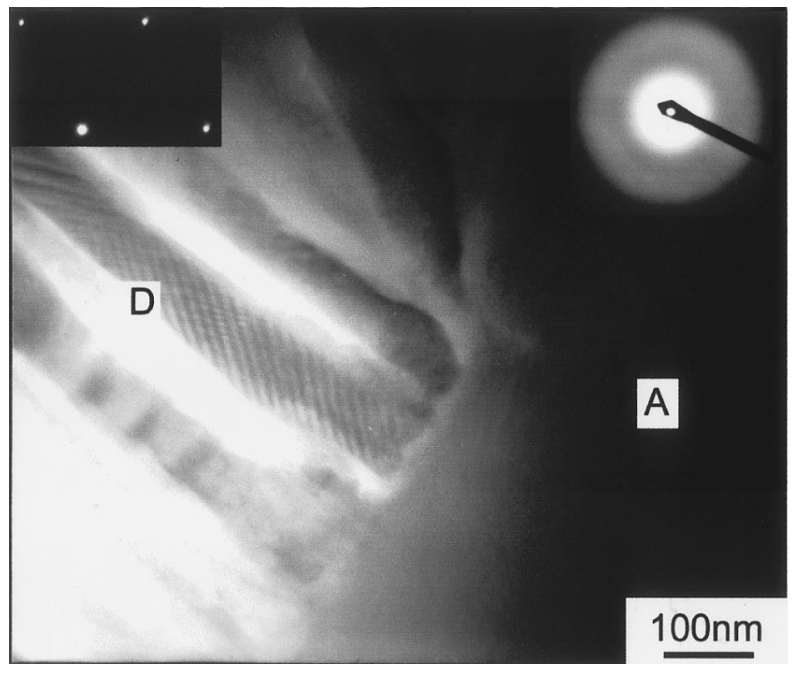

Fig. 4-TEM image showing the amorphous phase.

Figure 4 is TEM images showing the amorphous phase in the zirconium-contained zone of the pool. The amorphous phase indicated by mark A often exists near the austenite dendrite indicated by $\mathrm{D}$. The bright-field image of the amorphous phase is of a structureless feature. The left and right upper corners are selected area diffraction patterns (SADPs) 


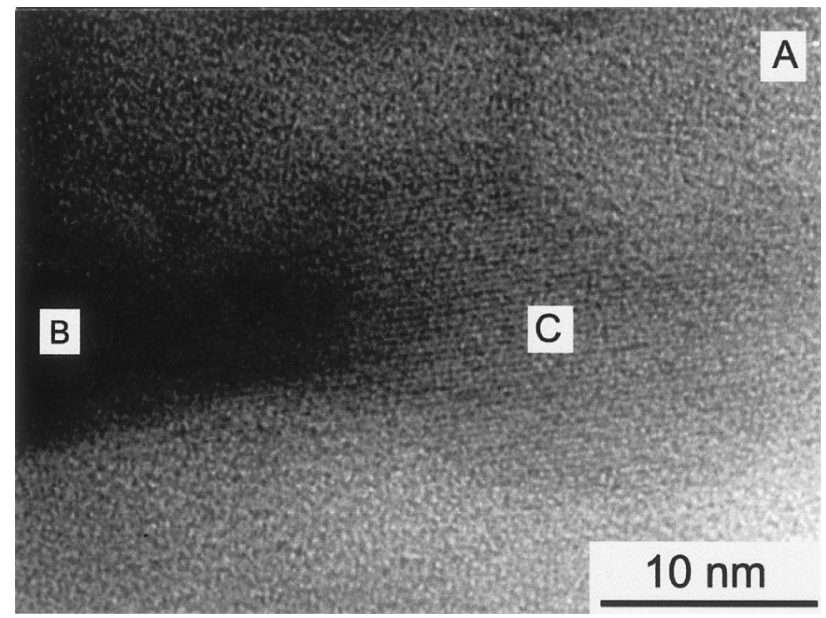

Fig. 5-HRTEM image showing the amorphous phase.

of the austenite and amorphous phases, respectively. The SADP of the amorphous phase shows a broad diffuse halo. The ring has a nearest neighbor distance of the order of $0.203 \mathrm{~nm}$, typical of an iron-based amorphous alloy. The $\mathrm{Zr}$ compositions are determined by EDXA to be 10.3 and 3.6 at. pct for the amorphous phase and the nearby austenite, respectively. It is indicated that the $\mathrm{Zr}$ composition of the amorphous phase is much higher than that of austenite. And, the $\mathrm{Zr}$ composition is uneven within the same region of the amorphous phase, ranging from 8.8 to 12.6 at. pct. Figure 5 is the HRTEM image showing the coexistence of the amorphous phase and adjacent austenite. The EDXA indicates that the $\mathrm{Zr}$ composition of the amorphous phase is 10.3 at. pet at A, higher than that of austenite, 3.2 and 4.6 at. pct, at B and $\mathrm{C}$, respectively. Therefore, the amorphous phase forms in $\mathrm{Zr}$-rich regions. Further analyses of a large quantity of amorphous phases indicate that the amorphous phase has a zirconium composition ranging from 7.6 to 16.8 at. pct, similar to that of $\mathrm{Fe}-\mathrm{Zr}-\mathrm{Ni}$ amorphous alloys obtained by Inoue et al. ${ }^{[14]}$

The TEM observation reveals that the amorphous phase occurs only in the zirconium-contained zone of the pool, i.e., in a depth of about $16 \mu \mathrm{m}$ below the surface. The amorphous phase has a scattered distribution. Continuous and large-scale areas of the formation of the amorphous phase are not seen.

The transition from the crystalline to the amorphous state within the $\mathrm{Zr}$-contained region confirms that the change of the composition causes the transition. The amorphous phase consists of multielements, e.g., $\mathrm{Zr}, \mathrm{Fe}, \mathrm{Ni}, \mathrm{Cr}$, and $\mathrm{Ti}$. The atom radii of $\mathrm{Zr}$ and $\mathrm{Fe}(\mathrm{Ni})$ are 0.158 and 0.124 (0.125) $\mathrm{nm}$, respectively. The large difference between atom sizes because of $\mathrm{Zr}$ addition restrains the nucleation of the crystalline phase and results in an increase in the glass formation ability. The Zr addition also increases the electronegativity and bond energy, which increases the interaction among atoms and the short-distance order in liquids. Thus, in the present investigation, the formation of the amorphous phase is due to the addition of zirconium.

\section{Hardness}

Figure 6 shows the variation of hardness as a function of the depth. It is seen that the hardness increases from 1.8 to

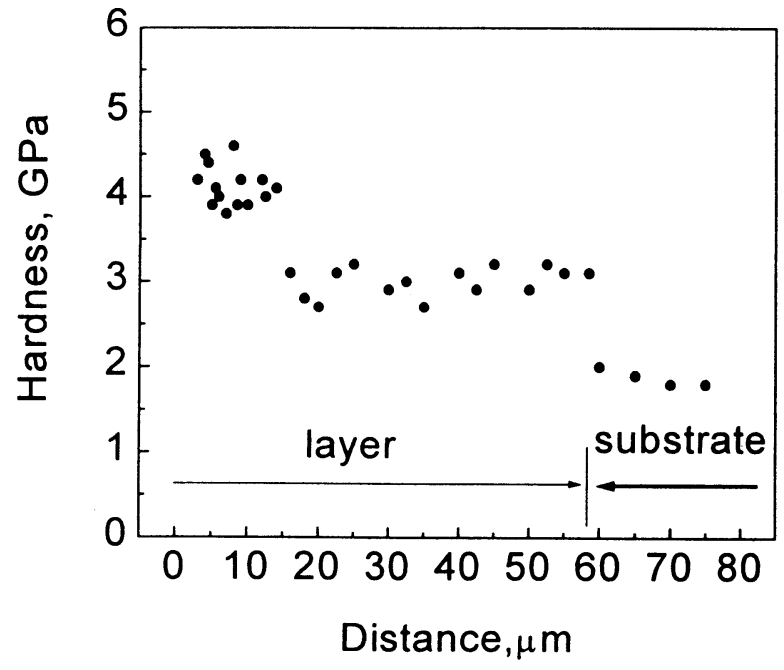

Fig. 6-Distribution of hardness as a function of the depth of the pool.

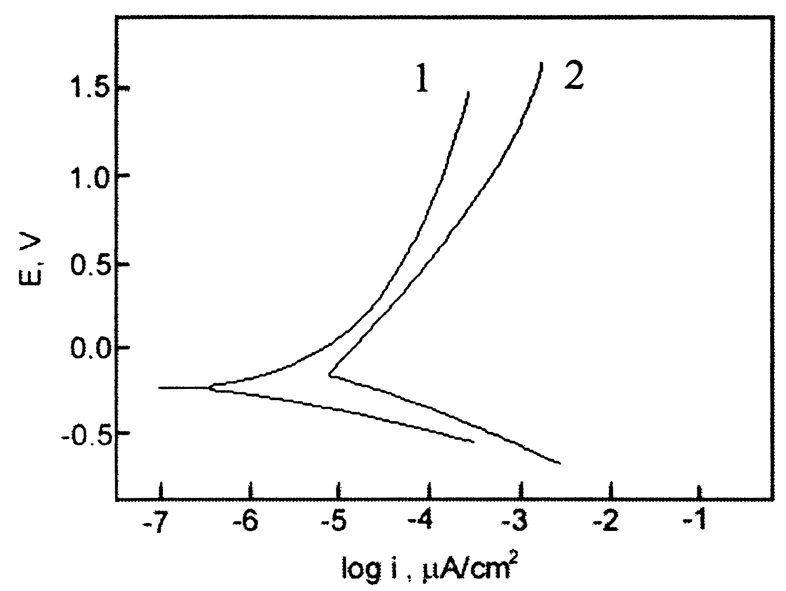

Fig. 7-Polarization curves: (1) laser-alloyed layer, and (2) original substrate.

2.1 GPa of the substrate to 2.6 to $3.2 \mathrm{GPa}$ of the pool without $\mathrm{Zr}$. This is because of the refinement of the microstructure and the formation of a high density of fine structures. The hardness increases to 3.8 to $4.6 \mathrm{GPa}$ in a depth of about 16 $\mu \mathrm{m}$ below the top surface. This is attributed mainly to the formation of the amorphous phase in the $\mathrm{Zr}$-rich region.

\section{Wear-Corrosion Resistance}

Figure 7 shows polarization curves with wear for the alloyed and original surface, respectively. The current density of the alloyed surface reduces remarkably, as compared with that of the original surface. So, the corrosion resistance with wear enhances for the alloyed surface. The measured wear-corrosion speeds are $7.3 \times 10^{-5}$ and $21.4 \times 10^{-5} \mathrm{~g} /$ $\mathrm{mm}^{2} \mathrm{~h}$ for the alloyed and original surface, respectively. The amorphous phase is of high hardness and excellent corrosion resistance. The grain refinement because of rapid solidification may effectively strengthen and purify the grain boundary and enhance the hardness. Therefore, the $\mathrm{Zr}$-alloyed surface with the formation of the amorphous phase has excellent corrosion and wear-corrosion resistance, as compared with the original surface. 


\section{CONCLUSIONS}

The new and original method has been successfully applied to prepare the coating containing the amorphous phase on an austenite stainless steel surface with pulsed Nd:YAG laser alloying zirconium nanoparticles. The coating is dual-phase microstructures consisting of the amorphous phase and austenite.

The refinement of cells and dendrites of austenite occurs due to ultrahigh cooling rate. And, pulsed laser alloying produces zirconium-contained regions in a depth of about $16 \mu \mathrm{m}$ below the free surface, as compared with the total depth of the pool of about $60 \mu \mathrm{m}$. The amorphous phase presents at zirconium-rich regions, with $\mathrm{Zr}$ composition ranging from 7.6 to 16.8 at. pct. The value of the average $d$ spacing of the first diffuse ring of the noncrystalline phase is $0.203 \mathrm{~nm}$. The mechanism of the formation of the amorphous phase is attributed to an increase of amorphous forming ability by zirconium addition. In addition, the corrosion and wear-corrosion resistance of the irradiated layer is evidently enhanced.

\section{ACKNOWLEDGMENTS}

This research was supported by the National Natural Science Foundation (Grant No. 19891180), the National Outstanding Youth Scientific Award of China (Grant No. 19525205), and The Chinese Academy of Sciences (Grant No. KJ951-1-201).

\section{REFERENCES}

1. D.S. Rickerby and A. Matthews: in Advanced Surface Coatings: a Handbook of Surface Engineering, D.S. Rickerby and A. Matthews, eds., Blackie, Glasgow, 1991, pp. 1-13.

2. J. Mazumder: in Surface Treatment and Film Deposition, J. Mazumder, O. Conde, R. Villar, and W. Steen, eds., Kluwer Academic Publishers, Dordrect/Boston/London, NATO ASI Series E: Applied Sciences, 1996, vol. 307, pp. 47-75.

3. J.D. Ayers and T.R. Tucker: Thin Solid Films, 1980, vol. 73, pp. 201-09.

4. T.H. Kim and B.C. Kim: J. Mater. Sci., 1992, vol. 27, pp. 2967-73.

5. F. Laroudie, C. Tassin, and M. Pons: J. Mater. Sci., 1995, vol. 30, pp. 3652-57.

6. C. Rieker, D.G. Morris, and J. Steffen: Mater. Sci. Technol., 1989 , vol. 5, pp. 590-96.

7. M. Tomie, N. Abe, S. Noguchi, Y. Kitahara, and Y. Sato: Trans. JWIR, 1991, vol. 20, pp. 43-49.

8. A.B. Lysenko, N.N. Kozina, T.V. Gulyaeva, V.V. Shibaev, and A.G Glushkov: Metallovedenie Termichekaya Obrabotka Metalloy., 1991, vol. 3, pp. 2-9.

9. C. Marsden, D.R.F. West, and W.M. Steen: in Laser Surface Treatment of Metals, C.W. Draper and P. Mazzoldi, eds., NATO ASI Series E, Martinus Nijhoff Publishers, Boston, MA, 1986, No. 115, pp. 461-73.

10. K.P. Kooper, P.L. Slebodnick, and E.D. Thomas: Mater. Sci. Eng., 1996, vol. A206, pp. 138-49.

11. K.P. Kooper, P.L. Slebodnick, K.E. Lucas, and E.A. Hogan: J. Mater. Sci., 1998, vol. 33, pp. 3805-16.

12. D.G. Morris: Mater. Sci. Eng., 1988, vol. 97, pp. 177-80.

13. F. Hirose, M. Takagi, H. Mori, Y. Kitoh, and T. Imura: Jpn. J. Appl. Phys., 1992, vol. 31, pp. 3940-45.

14. A. Inoue, H. Tomioka, and T. Masumoto: J. Mater. Sci., 1981, vol. 16, pp. 1391-1401. 